\title{
1
}

\section{INTRODUCTION TO ASSESSMENT IN REHABILITATION}

DAVID R. STRAUSER | CHELSEA E. GRECO

\section{LEARNING OBJECTIVES}

After reviewing this chapter, the reader should be able to:

- Describe the purpose of assessment in rehabilitation counseling and apply the problemsolving model.

- Describe the key terms and types of assessment typically used in rehabilitation counseling assessment.

- Define contemporary issues that have emerged regarding the use of assessment in rehabilitation counseling practice.

\section{Introduction}

Historically, assessment has been an important part of the rehabilitation process and has been viewed as critical service directed at enhancing rehabilitation outcomes of persons with all types of disability (Andrew, 1981; Chan, Reid, et al., 1997). The chapter introduces the role of assessment in contemporary rehabilitation counseling practice and describes a problem-solving process that can be employed by rehabilitation counselors to help guide the assessment process. Important terms are defined, and types of assessments that are relevant in rehabilitation counseling assessment are discussed. The chapter concludes with a discussion of the contemporary issues that have impacted and continue to have an impact on the use of assessment in rehabilitation counseling.

\section{Purpose of Assessment in Rehabilitation Counseling}

In an historical context, assessment has been viewed as the process of attempting to assess the client's aptitudes, achievement, intelligence, personality, interests, and behavior in an effort to determine potential goals and services needed to achieve desired rehabilitation outcomes (Andrew, 1981). In many environments, rehabilitation professionals are responsible for developing and implementing an evaluation strategy based on specific referral questions. A long-held view is 
that upon the completion of the assessment process, a rehabilitation counselor should obtain the following information that is relevant in developing an individualized rehabilitation plan: (a) the client's relevant levels of social, educational, psychological, and physiological functioning; (b) an estimate of the client's potential for behavior change; (c) the person's learning style; (d) specific education and training programs that might increase vocational potential; (e) jobs for which the client has the residual skills to perform without any additional training or skill development; (f) potentially feasible jobs for the client with additional training; and (g) community and auxiliary supports that can facilitate job acquisition and maintenance. Despite the ambitious expectation regarding the extent and quality of information gathered, it must be kept in mind that as with any good medical examination, information garnered from testing and evaluation is just one component of the assessment that should be used in planning and service provision (Strauser, Chan, Wang, Wu, \& Rahimi, 2014).

The primary purpose of assessment in rehabilitation counseling is to help the rehabilitation counselor and consumers obtain important and relevant information to help achieve identified goals and outcomes. In addition, participation in the assessment process should be a therapeutic experience that assists the client in making sense of things that have happened in the past, understanding the present situation, and identifying the tasks and behaviors needed to achieve identifiable goals and directions for the future (Strauser et al., 2014). In rehabilitation counseling, the primary focus of the assessment process is typically diagnostic, with the goal of helping the client engage in productive self-evaluation, increased awareness and understanding, and monitoring progress toward goal attainment. According to Gregory (2011), testing as part of the assessment process has the following five major objectives: classification, diagnosis and treatment planning, client self-knowledge, program evaluation, and research to guide theory and technique development. However assessment is being used in the rehabilitation counseling process, it is important to include the client in all phases of the assessment process, clearly convey the purpose of the testing, and work with the client in identifying meaningful and achievable goals and outcomes. Simply stated, the assessment process should be part of the learning process, not something that is supplementary to the counseling process (Hays, 2013).

Because assessment in rehabilitation counseling is typically a diagnosis-based problem-solving process, it is beneficial for rehabilitation counselors to utilize a concrete and straightforward problem-solving-based approach to identify the issues that will guide the assessment process. Clients involved in the assessment process will have different problem-solving abilities, but the utilization of a tangible process will maximize problem identification, individual involvement, and the potential utilization of the information obtained from the assessment process. A five-step, basic problem-solving model can be used by rehabilitation counselors throughout the assessment process to identify and process information related to the client's potential outcomes (Chang, D’Zurilla, \& Sanna, 2004; Hays, 2013). A description of each step follows:

Step 1: Problem Orientation-In this step, the rehabilitation counselor assesses how the problem is being viewed and whether the client recognizes the problem. When both parties are aware of the problem, they can work together to approach the problem in a systematic fashion.

Step 2: Problem Identification - In this step, both the rehabilitation counselor and the client work together to operationalize the problem in as much detail as possible. Research has found that clients are more likely to continue in the rehabilitation process if they have a clear understanding of the nature of the problem (Busseri \& Tyler, 2004). 
Identification of the problem also assists the rehabilitation counselor in communicating with other stakeholders such as referral sources, agency personnel, family, and other related professionals.

Step 3: Generation of Alternatives-Once the problem has been clearly identified, the rehabilitation counselor and the client can generate alternatives that can be used to help resolve the problem. In this step, the assessment process is used to help identify the client's personal strengths that can be leveraged to overcome difficulties and enhance individual development.

Step 4: Decision-Making-Once alternatives have been identified, the rehabilitation counselor and client can work together to anticipate the various consequences of the alternatives identified in step 3. In classical decision theory, choice can be conceptualized as the function of the probability of achieving success and the desirability of the outcome (Hays, 2013; Horan, 1979). According to this formula, the importance of assessing both the likelihood of success for the various alternatives and the attractiveness of those alternatives is emphasized with the understanding that clients will likely choose alternatives that maximize the likelihood of favorable outcomes (Hays, 2013).

Step 5: Verification-The final step of the decision-making process involves discussing with the client how both parties will be aware that the problem has been solved. This last step requires that the goals be clearly specified, that they be translated into specific behavioral objectives, and that the possibility for progress in accomplishing these goals be realistically viewed (Hays, 2013).

In addition to understanding how assessment can be used effectively in the rehabilitation counseling process, it is equally important to recognize the limitations of the assessment process. Tyler (1984) has provided an outline of the major limitations associated with the assessment process that can be applied to the rehabilitation counseling setting. First, tests do not measure unique characteristics but instead focus on common individual attributes. As a result, assessment and test results are not suitable for making group comparisons but only for approximating how well a person will function on the tested behavior in the culture for which the assessment is appropriate. Second, test scores do not exclusively measure specific human characteristics but instead note aspects of innate ability as influenced by the combination of cultural and environmental factors. Third, for many tests used in rehabilitation, a good score may mean the absence of disease or reduced functioning, rather than the possession of universal attributes to which most people aspire. Fourth, and perhaps most important, tests do not measure all traits and constructs equally, and test results are not necessarily indicative of the totality of a person's behaviors, attitudes, and skills (Hays, 2013).

\section{Important Terms in Rehabilitation Counseling Assessment}

In order for rehabilitation counselors to effectively use assessment and tests throughout the rehabilitation counseling process, they need to be aware of, and have command of, key terms that are used in the assessment process. In this section, the terms assessment, tests, measurement, and variable are defined. In addition, in rehabilitation counseling the term consumer and client is often used to refer to the person involved in the testing process. Also of note, the assessment process can take place in a variety of settings including, but not limited to, schools, community agencies, 
rehabilitation hospitals, mental health centers, colleges and universities, and vocational rehabilitation agencies. Brief descriptions of the four key terms follow.

Assessment-This all-encompassing term applies to the evaluation methods rehabilitation counselors use to measure characteristics of persons, places, and things (Hays, 2013). In addition, the terms appraisal and evaluation are often used interchangeably. The National Council on Measurement in Education (American Educational Research Association, American Psychological Association, and National Council on Measurement in Education, 1999) defines assessment as "any systematic method of obtaining information from tests or other sources used to draw inferences about the characteristics of people, objects, and programs" (p. 172). Two important aspects of this definition are important to consider. First, the definition implies that assessment utilizes a broad range of evaluation methods such as standardized tests, rating scales, observations, interviews, and record reviews as a means of obtaining information regarding the person being assessed. Second, the definition emphasizes the use of data derived from the assessment process to assist the rehabilitation counselor in understanding the person and the contextual issues impacting his or her specific situation. Overall, the term assessment is all encompassing in that it refers to the selection, administration, and interpretation of assessment results to develop hypotheses and specific questions related to the client's issues and possible approaches and services to promote insight, growth, and behavior change.

Test-Test refers to a specific instrument or technique used in the assessment process that obtains information in a systematic and often standardized manner to describe the behavior, feeling, attitude, thought, trait, or other constructs of interest. In rehabilitation counseling practice, tests are typically used to obtain data regarding an individual client's intelligence, ability, interests, personality, and physical and mental health functioning. In addition, tests can be considered self-referenced when the results are compared with the person's previous performance, criterion referenced when results are compared with a specific benchmark or standard, and norm referenced when results are compared with those of a standardized sample (Bolton \& Parker, 2008; Drummond \& Jones, 2010; Hays, 2013; Whiston, 2016).

Measurement-In rehabilitation counseling assessment, measurement refers to the process of operationalizing the variable of interest through the assignment of numerals or other appropriate units according to a set scale of measurement (i.e., nominal, ordinal, interval, and ratio; Bolton \& Parker, 2008).

Variable-Variable refers to a "construct or concept that can take on more than one value" (Hays, 2013, p. 6). Categorical variables are qualitative in nature and often include groupings such as gender, ethnicity, and socioeconomic class. In contrast, continuous variables typically use quantitative units to measure across a spectrum and may include test scores, age, or rank. The terms independent, dependent, and extraneous designate specific types of variables that may be encountered indirectly in the assessment process. Consistent with how these variables are conceptualized in rehabilitation research, independent variable refers to a variable that is manipulated, dependent variable refers to outcome or response in relation to the independent variable, and extraneous (latent) variables often go unnoticed in the assessment process and can introduce error in the measurement process by impacting the dependent variable.

\section{Types of Assessment Methods}

In addition to being familiar with key terminology, rehabilitation counselors must be familiar with the major distinctions in assessments and any potential implications as they relate to the assessment process. In this section, individual versus group administration, standardized versus 
nonstandardized, and speed versus power tests are discussed. The assessment types such as rating scales, projective techniques, behavioral observations, interviews, biographical measures, and physiological measures also are introduced.

\section{Group Versus Individual Assessment}

Although some tests are designed specifically for individual administration only, numerous tests can be both individually and group administered. Group administration of a particular test allows for information to be obtained from multiple subjects over a relatively short period of time, which in turn increases efficiency and reduces cost. In turn, individual administration allows the rehabilitation counselor to be more sensitive to the client's needs and allows the examiner to be more flexible in identifying and implementing appropriate test modifications. For certain populations such as children and people with certain types of disabilities, it may be better to administer tests individually than in groups. One particular advantage of individual testing that is important in assessment regardless of the population is that individual administration allows for better observational data and behavioral observations.

\section{Standardized Versus Nonstandardized Assessment}

Standardized tests are considered to be the gold standard in overall assessment because they are considered the most reliable and valid. Specifically, when standardization is the key defining aspect of a specific test or assessment process, it implies that the particular test or assessment procedure must meet certain psychometric standards (reliability and validity), include uniform administration, utilize objective scoring, and apply to a representative normative group. Types of standardized tests used in rehabilitation assessment include, but are not limited to, intelligence, aptitude, achievement, personality, interest, and value inventories.

Nonstandardized measures also play an important role in rehabilitation counseling assessment and typically include assessment techniques such as rating scales, projective techniques, behavioral observations, and biographical techniques. Although nonstandardized tests are considered to be not as dependable as standardized approaches, they can produce valuable information regarding contextual issues that may not be addressed in standardized measures. When used in conjunction with standardized measures, nonstandardized approaches can provide needed depth and valuable information on topics that are not typically addressed or may be missed by standardized assessment procedures. The more flexible and qualitative-based approach can be incorporated easily into the overall counseling process and is extremely effective in promoting self-awareness. Nonstandardized techniques that may be beneficial to incorporate into rehabilitation counseling assessment include card sorts, project techniques, work simulation, and multidomain behavioral observation.

\section{Maximum Versus Typical Performance Tests}

One way of differentiating tests is by categorizing them into tests that are designed to measure a person's maximum performance versus tests that are designed to measure how subjects typically perform. Tests of maximum performance can be further divided into tests of power and speed. The key characteristic of power tests is that they contain items of varying difficulty that most subjects taking the test are expected to complete within the specified time limit (Bolton \& Parker, 2008). Specifically, according to Hays (2013), a test is considered a power test if $90 \%$ of the people for whom the test is designed can complete the test within the time limits. Although speed may be a 
factor for some people, speed is not considered to be a primary influence on the score. In contrast to power tests, speed-based tests place a heavy emphasis on the speed of the subject's response. Speed tests usually contain a group of easy-to-finish tasks based on a homogeneous construct that are designed to be completed quickly. Examples of speed tests include tests of finger dexterity (e.g., Purdue Pegboard), clerical speed, and a majority of the work samples (e.g., Valpar Work Sample Series). Finally, tests of typical performance measure how subjects typically perform and what they typically prefer. Sometimes these tests may be referred to as tests of preference. Tests falling into this category include career interest, value, and most personality measures.

\section{Interviews}

The interview is one of the most common forms of assessment used in the rehabilitation counseling process (Berven, 2008) and can be categorized as structured, semistructured, or unstructured. Structured interviews utilize a standardized set of questions to solicit information from the client. Structured interviews offer some form of standardization resulting in increased reliability and validity at the expense of flexibility or clinical judgment that can be used to probe deeper into issues or topics that may arise during the interview. Unstructured interviews provide the most flexibility, sacrificing reliability and validity, and allow the rehabilitation counselor to fully explore areas deemed to be important based on developments during the actual interview. A drawback of unstructured interviews is that rehabilitation counselors may run the risk of focusing too much on one topic while failing to gather necessary information. A hybrid approach and probably the most commonly used approach in rehabilitation counseling is the semistructured interview. In using a semistructured interview format, rehabilitation counselors are able to blend elements from both structured and unstructured formats, providing needed structure while allowing the rehabilitation counselor the freedom to explore areas of interest in more detail.

\section{Biographical Data}

Like interviews, the review of biographical or demographic data is a primary source of information for the rehabilitation counselor, especially early in the counseling process. Reviewing medical, demographic, work, and educational records provides valuable insight into the client and his or her level of functioning and past performance. As noted by Hays (2013), a key maxim regarding biographical data is that the "best predictor of future performance is past performance." Although the information obtained from record and file review may be robust, it can also be limited because of failure to consider or minimize contextual factors influencing performance and behavior.

\section{Behavioral and Situational Assessments}

Behavioral and situational assessments are used in rehabilitation counseling settings to observe people engaged in simulated or actual activities, typically involving work-related or social tasks or behaviors. To record observations, rating scales are used to provide subjective estimates of a person's behaviors or characteristics and typically include pre- and posttest evaluations. Because behavioral and situational assessments are subjectively based, they have a higher risk of incurring errors that may affect the findings. Three types of error are of particular concern and should be guarded against. The halo effect is seen when raters show a tendency to generalize findings in one area to other areas of the subject. For example, if the person undergoing assessment is viewed as friendly and easy to get along with, he or she may also be viewed positively in other areas as well such as being bright and having potential for being a good leader (Hays, 2013). The error of 
central tendency and the leniency effect are reciprocal versions of each other. With the error of central tendency, an observer tends to rate all behaviors or tasks as average. In contrast, the leniency effect is seen when an observer rates things more favorably than what they actually are. To combat these errors, Hays (2013) recommends that the following five strategies be implemented in assessments involving observations: (a) use raters who are familiar with the person being evaluated, (b) require multiple behavioral observations, (c) obtain ratings from more than one observer, (d) use characteristics that are publicly observable, and (e) identify behaviors for observation that are related to the characteristic in question.

\section{Issues Regarding Assessment in Rehabilitation}

As mentioned at the beginning of this chapter, the use of assessment as part of the rehabilitation counseling process has a long history. However, recently the use of assessment as part of rehabilitation counseling process has been questioned with expressed concerns regarding the utility and predictive value of the results. Issues regarding utility and applicability have been particularly voiced regarding people with severe disabilities. In this section, issues impacting the assessment process in rehabilitation are discussed addressing both the pros and cons, with an emphasis on the many benefits of using assessment in assisting rehabilitation professionals in determining the type and intensity of services needed to facilitate appropriate outcomes for people with disabilities.

\section{Criticisms and Limitations}

One of the primary philosophical underpinnings of assessment in rehabilitation counseling has been the focus on the individual client. With this focus, the primary goal has been to assist clients in obtaining information to facilitate a better understanding of themselves as individuals and to increase overall participation in society. A core value of the rehabilitation counseling-based approach to assessment is that when clients take an active role in the assessment process, they better understand the information generated and how the information is used to guide decisions about interventions and services for an optimal outcome. Ultimately, this should lead them to take a more active role in their own rehabilitation and self-development (Strauser, 2014). However, as with many medical and rehabilitation settings, involving the client in the process is often overlooked or minimized. The client then becomes an object of evaluation instead of a participant in the evaluation process-that is, an observer and consumer, rather than an active participant taking ownership and investing in the evaluation and rehabilitation process. As a result, some rehabilitation professionals have questioned the application of assessment in rehabilitation planning and have argued that assessment may be disempowering to clients participating in the rehabilitation process. Therefore, the perception of assessment is that it has limited utility in facilitating rehabilitation outcomes for people with severe disabilities (Bond \& Dietzen, 1990).

Another criticism and more significant issue that has been levied against the use of assessment is that testing clients with disabilities lacks predictive value in determining viable rehabilitation outcomes (Szymanski \& Parker, 2003). Specifically, researchers and practitioners who work with clients with severe cognitive and psychiatric disabilities and clients from diverse cultural backgrounds have been the most vocal in expressing this view of the perceived lack of efficacy regarding the use of traditional assessment. From the perspective of providers who work with people with severe disabilities, their argument appears to have some merit. For many who work with people with severe disabilities, the only potential use of any standardized assessment procedure may be, under certain circumstances, to provide relevant documentation in determining 
eligibility for benefits or services. It makes sense that for clients who have physical, cognitive, and affective symptoms that significantly limit functioning and ability to live and work independently without significant ongoing support, traditional assessment approaches might not be beneficial. However, for those with mild to moderate disabilities, by far the largest group of persons with disabilities, information obtained from assessment may provide important information to facilitate greater individual understanding, encourage exploration, and identify potential educational, social, interpersonal and employment opportunities that were not recognized previously.

Cultural and gender bias and discrimination have also been noted as limiting factors related to the use of assessment in rehabilitation counseling. Cultural limitations, especially those linguistic in nature, present a barrier to the use and productive nature of any evaluation, including interviews and ecologically and environmentally based evaluation. Cultural and linguistic factors must be considered in all phases of the rehabilitation process. Issues related to lack of representation of diverse groups during test construction and norming historically have been limiting factors negatively impacting the utility of many psychological instruments used in assessment. However, most evaluation instruments, including work samples, have attempted to address the limitations associated with gender and cultural limitations, and new instruments and procedures have been developed that take cultural issues into account (Strauser et al., 2014).

Finally, many rehabilitation practitioners and researchers have argued that using assessment to gauge ability significantly underestimates capacity to function from a skill perspective. Specifically, providers argue that aptitude and achievement levels are not relevant in determining employment skill in light of rehabilitation approaches such as supported and customized employment that provide wraparound services to people with severe disabilities to facilitate job acquisition and initial job maintenance. Instead, on-the-job training and the place and train approach may be the most relevant models to develop specific employment skills related to specific employment settings. Again, for people with severe disabilities, this is certainly true and would appear to be the most effective.

\section{Advantages and Merits}

Although the aforementioned criticisms have merit and apply to certain populations served by the rehabilitation community, those criticisms regarding the utility of assessment may not have broad application for a variety of important reasons. First, as previously noted, a majority of people with disabilities who are engaged in the rehabilitation process do not qualify as having a severe disability. Based on the concept of inclusion and empowerment that provides the basis of a rehabilitation counseling approach to assessment, clients should actively be involved in all phases of the evaluation process. The working alliance provides the foundation for the counseling approach to evaluation wherein the emphasis is on building a solid relationship with the individual, developing realistic and obtainable goals, and determining what tasks lead to goal accomplishment (Strauser, Lustig, \& Donnell, 2004; Strauser et al., 2014). Considerable evidence has found that a well-developed working alliance leads to better rehabilitation outcomes for persons with disabilities (Chan, Shaw, McMahon, Koch, \& Strauser, 1997; Donnell, Lustig, \& Strauser, 2004; Lustig, Strauser, Weems, Donnell, \& Smith, 2003; Strauser et al., 2014). When assessment is approached with the working alliance as a foundation, the focus should first be directed at developing a relationship with the individual that will contribute to accomplishing effective goals and tasks. This has particular application to persons who have disabilities but also have the residual ability to obtain and maintain rehabilitation outcomes with minimal or no onsite support. 
Second, regarding the career development and employment of persons with disabilities, three primary factors are recognized (Conte, 1983; Strauser, O’Sullivan, \& Wong, 2010; Szymanski \& Hershenson, 2005). First, people with disabilities may not have had many career exploration experiences, and as a result they may have a narrow view of the world of work and available employment options. Second, people with disabilities may have fewer opportunities to develop effective career decision-making skills. The lack of such skills may in turn impair the development of the ability to identify and process information that is needed to make decisions and integrate relevant personal and contextual information. Third, people with disabilities may have a negative self-concept regarding career and employment because of negative societal attitudes toward those with disabilities, creating stigma and negative perceptions of employers. As a result, they may have a restricted view of viable career and employment options. When assessment is integrated into the overall rehabilitation counseling process, it can provide the client with the information necessary to engage in self-exploration regarding personal traits and how they relate to work and other areas of participation such as community, home, and social. Information obtained from assessment can provide a client with an opportunity to engage in the decision-making process with appropriate support and information, and increase self-confidence, concept, and efficacy as it relates to participating in career development and employment activities. When assessment results are used as part of the rehabilitation counseling process, they provide a framework or structure for examining and expanding rehabilitation options.

Third, research over the last 30 to 40 years has consistently shown that people with disabilities may not achieve appropriate rehabilitation outcomes for social, interpersonal, and contextual reasons, not from lack of skill or abilities (Wright, 1980). Therefore, there may be some logic in the criticism that skill-based assessment lacks predictive validity in determining appropriate goals and tasks related to achieving desired rehabilitation outcomes. However, assessment of personality, values, and interests may be particularly relevant in helping facilitate a client's development and identify appropriate and meaningful rehabilitation outcomes (Strauser, 2014). One common misperception of many practitioners is that the purpose of the assessment process is to diagnose a condition (e.g., depression) or determine a match between a client and a specific position or environment. Rehabilitation counselors should not endorse this view and instead should subscribe to an adjustment-based approach, which focuses on the dynamic, reciprocal, and continuous interaction between the person and the environment. Applying the principles of individual adjustment, one is concerned not only about initial diagnosis or match but about the person's ability to adjust to the changing demands of the environment and his or her own continued personal development and maturation (Strauser et al., 2014). Interests, personality, and values are critical components related to the ability to adjust to and meet the contextual demands of the environment. Evaluation of these constructs can provide the client with critical information that may not be readily available through introspection and self-analysis. In addition, assessment information can provide reinforcement of previously identified values, interests, and personality traits. Overall, obtaining this information is critical in facilitating effective individual adjustment.

Finally, research in the area of personality, values, and interests has provided empirical support that these constructs are significantly more robust predictors of career development and employment than ability for all people, including those with disabilities (Murdock \& Rounds, 2014; O'Sullivan, 2014; Su \& Rounds, 2014). When incorporated as part of the assessment and rehabilitation counseling process, information regarding these constructs should be used to facilitate self-exploration. 


\section{Conclusions}

The primary purpose of this chapter was to introduce the role of assessment in contemporary rehabilitation counseling practice. A five-step, problem-solving approach consisting of problem orientation, problem identification, generation of alternatives, decision-making, and verification was introduced to help guide the rehabilitation assessment process. This chapter also introduced assessment, test, measurement, and variable as key terms that are relevant in rehabilitation counseling assessment and described the different types of assessment methods typically used. The chapter finished with a discussion of the contemporary issues that have emerged regarding the use of assessment in rehabilitation counseling. The introduction of these important issues and concepts related to assessment should provide rehabilitation counselors with the necessary basic understanding to be informed implementers and consumers of assessment in rehabilitation counseling. In addition, rehabilitation counselors who are familiar with the pros and cons associated with assessment in rehabilitation counseling will be more likely to use rehabilitation assessment to maximize individual outcomes.

\section{References}

American Educational Research Association, American Psychological Association, and National Council on Measurement in Education. (1999). Standards for educational and psychological testing. Washington, DC: Author.

Andrew, J. W. (1981). Evaluation of rehabilitation potential. In R. M. Parker \& C. E. Hansen (Eds.), Rehabilitation counseling: Foundations-consumers-service delivery (pp. 205-226). Boston, MA: Allyn \& Bacon.

Berven, N. L. (2008). Assessment interviewing. In B. Bolton \& R. Parker (Eds.), Handbook of measurement and evaluation in rehabilitation (pp. 243-261). Austin, TX: Pro-Ed.

Bolton, B., \& Parker, R. (Eds.). (2008). Handbook of measurement and evaluation in rehabilitation. Austin, TX: Pro-Ed.

Bond, G., \& Dietzen, L. (1990). Predictive validity and vocational assessment: Reframing the question. In R. L. Glueckauf, L. Sechrest, G. Bond, \& E. McDonel (Eds.), Improving assessment in rehabilitation and health (pp. 61-86). Newbury Park, CA: Sage.

Busseri, M. A., \& Tyler, J. D. (2004). Client-therapist agreement on target problems, working alliance, and counseling outcome. Psychotherapy Research, 14, 77-88. doi:10.1093/ptr/kph005

Chan, F., Reid, C., Roldan, G., Kaskel, L., Rahimi, M., \& Mpofu, E. (1997). Vocational assessment and evaluation of people with disabilities. Physical Medicine and Rehabilitation Clinics of North America, 8(2), 311-325. doi:10.1016/S1047-9651(18)30328-0

Chan, F., Shaw, L., McMahon, B. T., Koch, L., \& Strauser, D. (1997). A model for enhancing consumer-counselor working relationships in rehabilitation. Rehabilitation Counseling Bulletin, 41, $122-137$.

Chang, E. D., D’Zurilla, T. J., \& Sanna, L. J. (2004). Social problem solving: Theory, research, and training. Washington, DC: American Psychological Association.

Conte, L. (1983). Vocational development theories and the disabled person: Oversight or deliberate omission? Rehabilitation Counseling Bulletin, 26, 316-328.

Donnell, C., Lustig, D. C., \& Strauser, D. R. (2004). The working alliance: Rehabilitation outcomes for persons with severe mental illness. Journal of Rehabilitation, 70(2), 12-17.

Drummond, R. J., \& Jones, K. D. (2010). Assessment procedures for counselors and helping professionals (7th ed.). Upper Saddle River, NJ: Pearson/Merrill Prentice Hall.

Gregory, R. (2011). Psychological testing: History, principles, and applications (6th ed.). Needham Heights, MA: Allyn \& Bacon.

Hays, D. G. (2013). Assessment in counseling: A guide to the use of psychological assessment procedures (5th ed.). Alexandria, VA: American Counseling Association. 
Horan, J. J. (1979). Counseling for effective decision-making: A cognitive-behavioral perspective. North Scituate, MA: Duxbury Press.

Lustig, D. C., Strauser, D. R., Weems, G. H., Donnell, C., \& Smith, L. D. (2003). Traumatic brain injury and rehabilitation outcomes: Does working alliance make a difference? Journal of Applied Rehabilitation Counseling, 34(4), 30-37.

Murdock, C., \& Rounds, J. (2014). Work values: Understanding and assessing motivation to work. In D. R. Strauser (Ed.), Career development, employment, and disability in rehabilitation (pp. 193-206). New York, NY: Springer Publishing Company.

O’Sullivan, D. (2014). Personality development, expression, and assessment for work adjustment considerations in rehabilitation contexts. In D. R. Strauser (Ed.), Career development, employment, and disability in rehabilitation (pp. 77-96). New York, NY: Springer Publishing Company.

Strauser, D. R. (2014). Career development, employment and disability in rehabilitation: From theory to practice. New York, NY: Springer Publishing Company.

Strauser, D. R., Chan, F., Wang, M., Wu, M., \& Rahimi, M. (2014). Vocational evaluation in rehabilitation. In D. R. Strauser (Ed.), Career development, employment, and disability in rehabilitation (pp. 179-192). New York, NY: Springer Publishing Company.

Strauser, D. R., Lustig, D. C., \& Donnell, C. (2004). The impact of the working alliance on therapeutic outcomes for individuals with mental retardation. Rehabilitation Counseling Bulletin, 47, $215-223$. doi:10.1177/00343552040470040301

Strauser, D. R., O’Sullivan, D., \& Wong, A. W. K. (2010). The relationship between contextual work behaviors self-efficacy and work personality: An exploratory analysis. Disability and Rehabilitation, 32(4), 1999-2008. doi:10.3109/09638281003797380

Su, R., \& Rounds, J. (2014). Vocational interests. In D. R. Strauser (Ed.), Career development, employment, and disability in rehabilitation (pp. 207-222). New York, NY: Springer Publishing Company.

Szymanski, E. M., \& Hershenson, D. B. (2005). An ecological approach to vocational behavior and career development of people with disabilities. In R. M. Parker, E. M. Szymanski, \& J. B. Patterson (Eds.), Rehabilitation counseling: Basics and beyond (pp. 225-280). Austin, TX: Pro-Ed.

Szymanski, E. M., \& Parker, R. M. (2003). Vocational assessment and disability. In E. M. Szymanski \& R. M. Parker (Eds.), Work and disability: Contexts and strategies in career development and job placement (pp. 155-200). Austin, TX: Pro-Ed.

Tyler, L. E. (1984). Testing the test: What tests don't measure. Journal of Counseling and Development, 63, 48-50. doi:10.1002/j.1556-6676.1984.tb02682.x

Whiston, S. (2016). Principles and applications of assessment in counseling (5th ed.). Belmont, CA: Brooks/Cole.

Wright, G. N. (1980). Total rehabilitation. Boston, MA: Little, Brown. 